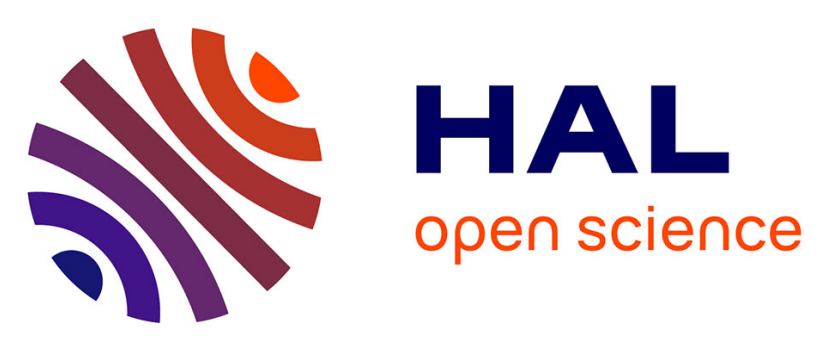

\title{
Simulation Based Optimization of Lot Sizes for Opposing Logistic Objectives
}

Janine Tatjana Maier, Thomas Voss, Jens Heger, Matthias Schmidt

\section{To cite this version:}

Janine Tatjana Maier, Thomas Voss, Jens Heger, Matthias Schmidt. Simulation Based Optimization of Lot Sizes for Opposing Logistic Objectives. IFIP International Conference on Advances in Production Management Systems (APMS), Sep 2019, Austin, TX, United States. pp.171-179, 10.1007/978-3030-29996-5_20. hal-02460489

\section{HAL Id: hal-02460489 \\ https://hal.inria.fr/hal-02460489}

Submitted on 30 Jan 2020

HAL is a multi-disciplinary open access archive for the deposit and dissemination of scientific research documents, whether they are published or not. The documents may come from teaching and research institutions in France or abroad, or from public or private research centers.
L'archive ouverte pluridisciplinaire HAL, est destinée au dépôt et à la diffusion de documents scientifiques de niveau recherche, publiés ou non, émanant des établissements d'enseignement et de recherche français ou étrangers, des laboratoires publics ou privés. 


\title{
Simulation based optimization of lot sizes for opposing logistic objectives
}

\author{
Janine Tatjana Maier, Thomas Voß, Jens Heger, Matthias Schmidt \\ Institute of Product and Process Innovation, Leuphana University of Lüneburg, \\ 21335 Lüneburg, Germany \\ (janine tatjana.maier, thomas.voss, jens.heger, mat- \\ thias.schmidt)@leuphana.de
}

\begin{abstract}
The objective of this study is to optimize the lot sizes for three different products based on storage cost, set up cost and logistic key performance indicators (KPIs) such as delivery reliability. Two methods including a mathematical model and the static method of Andler's lot size were originally used to solve this problem. However, both methods produce lot sizes that underperform according to logistic KPIs. For that reason, a simulation considering dynamic behavior and logistic performance is developed to heuristically optimize the lot sizes while being restricted to a minimum standard of delivery reliability. The study indicates that modifying the lot sizes will improve the logistic performance without increasing the total costs drastically. Compared to Andler's static method, the heuristically-optimized lot sizes show an average increase of the delivery reliability by $7 \%$ and a reduction of the total cost by $13 \%$. Throughput time was raised by more than $25 \%$ and the utilization elevated by $4 \%$.
\end{abstract}

Keywords: Lot sizing, Simulation, Logistic objectives

\section{Introduction}

A lot size can be defined as the number of identical products processed on a production system without interruption [1]. If multiple products must be manufactured on the same machine and set ups are necessary, lot sizes should be determined to reduce set up times and total costs. A large lot size is accompanied by high storage costs throughout the supply chain. Thus determining economical lot sizes is a key task of production planning, control and remains a relevant issue in manufacturing [2]. This administrative task becomes apparently critical when considering capacity restrictions, time-variant demand and the increasing number of products and product variants. Also, the large volume of scientific research on solving lot sizing problems indicates the pertinence of this topic. The methods developed to address the lot sizing problem diverge in several directions, but they all strive to minimize the total set up and storage costs for a given demand. This study will add the logistic KPI delivery reliability to the problem and optimize the lot size to achieve $80 \%$ or higher delivery reliability. 
In the subsequent section, three different approaches for calculating lot sizes are presented including the static lot size calculation, a mathematical model and the discrete event simulation. The characteristics of the production system are described in section three. The superiority of the heuristic optimization approach is demonstrated in a comparison of all three approaches in section four. Section five concludes the study and outlines future research possibilities.

\section{Utilized approaches}

In numerous cases, Operations Research methods regarding the calculation of lot sizes are based on the Wagner-Whitin-algorithm [3] which is built on dynamic demands. These lot sizing models are categorized by a large number of characteristics including the number of products, the set up and shortage structure, capacity and resource restrictions, the number of levels and the planning horizon [4]. In the area of production planning and control, the base models by Harris [5] and Andler [6] were extended using logistic costs to develop new models.

Static lot size calculations are often used to show the general correlation between lot sizes and costs. Mathematical formulations provide a way to consider the interactions of different products while focusing on machine capacity. With an increasing time frame duration, rising number of product variants and representing real life scenarios, the complexity of the model increases. It is NP-hard after all. Additionally, discrete event simulations offer the possibility to evaluate dynamic system behavior based on the interactions of the generated agents. Combining the static calculations with dynamic system behavior and the implemented heuristic optimization provides the framework to conduct further analyses. In this study, the simulation model is also designed to evaluate logistic KPIs including delivery reliability.

\subsection{Static lot size calculation}

The multi-criteria lot sizing model by Münzberg [7] provides the general idea for the conducted study. Based on the models provided by Andler and Harris, Münzberg proposes a logistic cost factor (LF) representing the increased cost for storage to improve logistic performance and reduce lot sizes. In this approach, the logistic objectives include work-in-process, throughput time, schedule reliability and flexibility. The objectives are also considered logistic costs and are calculated to determine the economical and logistical optimal lot size from the LF and defined storage costs. The economic and logistical optimal lot size $X_{\text {opt }}$ used in this model can be determined mathematically as:

$$
X_{\text {opt }}=\sqrt{\frac{2 \cdot \text { setup costs } \cdot \text { demand }}{L F \cdot \text { holding rate } \cdot \text { production costs per unit }}}
$$

Münzberg discussed the estimation of the LF in great detail. The model can be used to identify the primary correlations between the lot size and the logistic objectives, but does not consider the secondary effect between the numerous different products interacting within the production system. 


\subsection{Mathematical model for the lot sizing problem}

The mathematical model of the proportional lot sizing problem is based on the approach by Drexl and Haase [8]. The goal is to find a policy that minimizes the average set up and storage costs in a long-term case. The following assumptions were made:

(1) The planning horizon is finite and all jobs are on the same priority level.

(2) The demand of each product in each time period is a discrete random variable based on a known overall percentage distribution between the products.

(3) All products are produced on a line with individual operation times.

(4) The set up costs and times of each product are known and not sequence dependent. The set up state can only be changed once during a period, but can be transferred into the next period.

(5) The storage costs vary for each product, but stay constant over all periods.

(6) The production of each product is independent from the other products and there is no delay from primary stages.

(7) The machine time is fixed and known, regardless of the percentage of use.

\section{Notation}

It is assumed the mathematical model for the lot sizing problem was developed using the following notations:

Input data

$d_{p, t} \quad$ demand of product $p$ in period $t$

$s c_{p} \quad$ set up costs for product $p$

$I_{p, o} \quad$ initial inventory of product $p$

$I_{p, T+1} \quad$ final inventory of product $p$

$o t_{p} \quad$ operation time of product $p$

$C t_{t} \quad$ machine time capacity in period $t$

$h c_{p, t} \quad$ unit inventory storage cost of product $p$ in period $t$
Indexes and sets

$$
\begin{array}{ll}
p=1, \ldots, P & \text { product } \\
t=1, \ldots, T & \text { period }
\end{array}
$$

Decision variables

$X_{p, t} \geq 0 \quad$ production of product $p$ in period $t$

$I_{p, t} \geq 0 \quad$ inventory of product $p$ in period $t$

$y_{p, t} \in\{0,1\} \quad$ binary set up variable, 1 if product $p$ is set up in period $t, 0$ otherwise

$\delta_{p, t} \in\{0,1\} \quad$ set up state variable, 1 if at the end of period $t$ product $p$ is set up, $O$ otherwise

Objective function

Given the assumptions presented in section 1, the objective is to minimize the sum of the set up costs and logistics costs for all products over all periods. The objective function only focuses on satisfying the demand while minimizing the total costs.

$$
\min Z=\sum_{p, t}\left(s c_{p} \cdot \gamma_{p, t}\right)+\sum_{p, t}\left(h c_{p, t} \cdot I_{p, t}\right)
$$


Inventory constraint

The inventory constraint ensures the previous period's inventory plus the current period's production will satisfy the demand. Considering the non-negative inventory in the current period, the production of a product can exceed the demand. This constraint must remain valid for all products and periods.

$$
I_{p, t-1}+X_{p, t}-I_{p, t}=d_{p, t}
$$

Capacity constraints

A constraint is necessary for capacity because machine time is limited in each period. The machine time capacity constraint guarantees the operation times for each product does not exceed the machine time capacity. Since the utilization ratio is not considered in this case, it is possible to have unused machine time.

$$
\sum_{p}\left(o t_{p} \cdot X_{p, t}+s t_{p} \cdot \gamma_{p, t}\right) \leq C t_{t}
$$

Set up constraints

The first constraint indicates the machine must be in the set up state for a specific product to produce it during the current period. This standard needs to be guaranteed for all products over all periods. The second constraint ensures a maximum of two products are produced during each period. It permits one set up per period stemming from the usage of micro periods. The last constraint shows that the set up state can be transferred from the previous period.

$$
\begin{gathered}
X_{p, t} \leq \frac{C t_{t}}{o t_{p}} \cdot\left(\delta_{p, t-1}+\delta_{p, t}\right) \\
\sum_{p} \delta_{p, t} \leq 1 \\
\delta_{p, t}-\delta_{p, t-1} \leq y_{p, t}
\end{gathered}
$$

\subsection{Discrete event simulation}

Simulation can be used to assist the planning of structures, processes and resources in a real factory [9] [10]. The simulation model establishes the impact of logistic objectives and consequently is limited to logistic processes which feature an intense connection to material flow.

The model is constructed using agent-based discrete event simulation with multiple variables for lot sizes enabling a perfect interaction with the optimization module. The optimization is conducted using the AnyLogic own optimization algorithm, minimizing the sum of storage- and set up costs. In this particular case, a restriction was introduced to achieve a reliability of approximately $80 \%$ delivery reliability. The authors conducted a short preliminary study which discovered 1,000 iterations with 30 replications yield feasible results for the optimization of the production scenario detailed in this paper. Generally 30 replications are considered a sufficient number to prove significance without extensive calculation time. 


\section{$3 \quad$ Production system and database}

In this study, a manufacturing system is analyzed which uses a mixed order handling strategy. The strategy, known from industry, is considered a make-to-order strategy with fixed lot sizes. In this scenario, the manufacturing systems does not have any safety stock.

The customer places an order and expects the product to be delivered in 30 minutes or less. Each time an order is placed, a request to storage is initiated. A sufficient inventory means the product is delivered straight to the customer. Otherwise, a new production job is created if the inventory is too low and no job containing this product is in the system. It should be noted only the optimal lot size, or a multiple of it, can be produced. Finished products that are not required are placed in stock.

To ensure a significant comparison with the other models, data used for the simulation study is based on an example of the mathematical formulation presented by Drexl and Haase [8]. The overall demand, an average of 250 products per demand profile, and the percent distribution of three different products is known. Prior to every simulation run, a new demand profile is generated varying in amount and period the demand occurs making the input to the model different for every run. Due to the comparison with the mathematical model, no warmup phase is considered and the runtime of the model must be 660 minutes. The number represents a production day, 10 periods with a machine capacity of 60 minutes each. Table 1 shows the exact values for the single products.

Table 1. Dataset for the simulation model

\begin{tabular}{llll}
\hline & Product 1 & Product 2 & Product 3 \\
\hline Average occurrence & $60 \%$ & $30 \%$ & $10 \%$ \\
Set up costs per set up & $10 €$ & $30 €$ & $25 €$ \\
Storage costs per product and period & $1.1 €$ & $2 €$ & $1.5 €$ \\
Operation time per product & $2 \mathrm{~min}$ & $1 \mathrm{~min}$ & $3 \mathrm{~min}$ \\
\hline
\end{tabular}

\section{$4 \quad$ Results}

In accordance with literature, the conducted study determines that lot size is not very cost sensitive for small deviations from the optimal value [11]. Furthermore, the study indicates that logistic KPIs are improved by a slight change of the lot size without a significant increase of the total costs.

The lot sizes determined by Andler's method, the mathematical model and heuristic optimization were recorded, compared and inserted into the simulation model. The simulation output includes values for the logistic objectives throughput time, delivery reliability, utilization and the economical KPI "total cost". On all defined products, the throughput time and distance to deadline were recorded for every order during the simulation. 
The recorded KPIs, especially delivery reliability, have been increased in this study without raising the total cost substantially. The calculated lot sizes are presented in Table 2. For the dynamic optimized lot sizes generated by the mathematical model, no general lot size can be derived in that particular case.

Table 2. Different lot sizing policies and the resulting logistic objectives.

\begin{tabular}{llll}
\hline & Product 1 & Product 2 & Product 3 \\
\hline Heuristic approach & 29 & 27 & 14 \\
Andler's lot size & 17 & 16 & 10 \\
\hline
\end{tabular}

It is shown that the heuristic optimization approach uses larger lot sizes for all three products, ranging up to $70 \%$ larger lot sizes for product 1 . This can potentially create large amounts of stored products and a reduced cumulative set up cost. In this case, the solution seems plausible due to low storage costs and a high one-time set up cost. The usage of a logistic factor, presented by Münzberg, would result in smaller lot sizes which contrasts to the heuristic solution. Possible reasons include order handling strategy and neglecting safety stocks in the model presented in this work.

For every lot sizing policy and the calculated lot sizes, multiple runs with different demand profiles were tested. Table 3 shows the mean output data of the simulation study which clearly shows the superior delivery reliability of the heuristically optimized lot size. Compared to the Andler's lot size the reliability increased by $7 \%$ while reducing the total cost by $13 \%$. On the other side, it increased the throughput time by more than $25 \%$ as well as the utilization by $4 \%$.

Table 3. Different lot sizing policies and the resulting logistic objectives.

\begin{tabular}{lllll}
\hline & $\begin{array}{l}\text { Delivery } \\
\text { Reliability }\end{array}$ & Total Cost & Throughput time & Utilization \\
\hline Mathematical model & $69 \%$ & $364 €$ & $26 \mathrm{~min}$ & $66 \%$ \\
Heuristic approach & $77 \%$ & $344 €$ & $55 \mathrm{~min}$ & $75 \%$ \\
Andler's lot size & $70 \%$ & $391 €$ & $41 \mathrm{~min}$ & $71 \%$ \\
\hline
\end{tabular}

After examining the interactions between the different lot sizes, a parameter variation experiment was conducted. The lot sizes of all three products were varied ranging from 5 to 30 in single unit steps. The results are presented in Fig. 1. In the figure, four plots are presented showing the delivery reliability compared to throughput time in differing cost ranges. Although the markers are widely scattered, general trends are recognizable. Every plot shows convergence to a maximum which is close to the desired customer delivery time (CDT). If the throughput time is below the CDT, it can be expected that smaller lot sizes were produced. For that reason, the amount of products in stock is reduced occasionally resulting in unfortunate combinations of production sequences resulting in lower delivery reliability. With increasing throughput time, a trend of decreasing delivery reliability can be detected. This results from the larger lot sizes overloading and clogging the system. 
With increasing total cost, the peak shifts to the right, representing higher throughput times. The trend, known from before, has a much steeper slope now. This could be caused by a clogged production system and an empty stock.

(a)

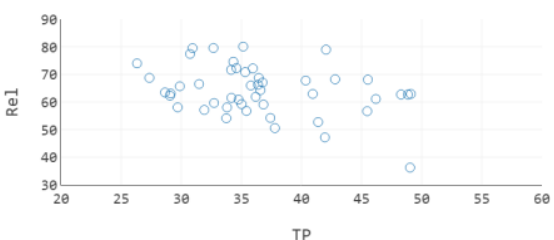

(c)

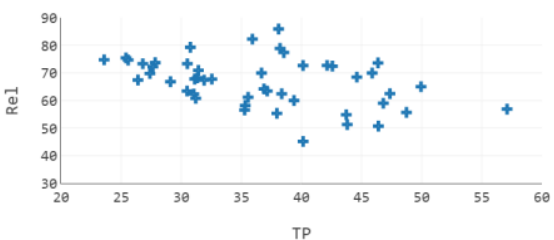

(b)

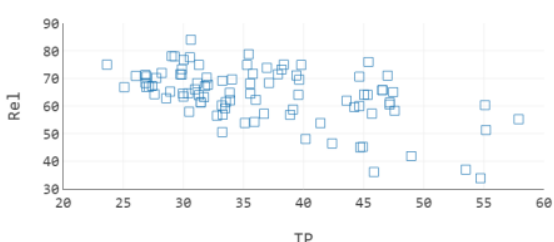

(d)

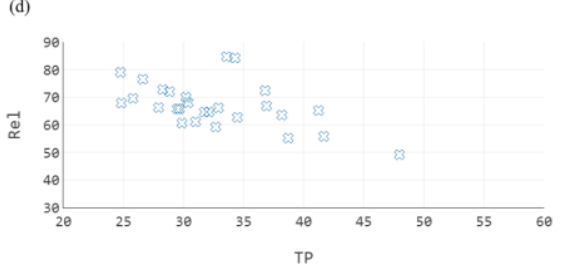

Fig. 1. The mean values of the parameter study varying the lot sizes of all three products. Every marker represents a specific combinations of lot sizes and the resulting throughput time (TP), Total Cost (TC) and delivery reliability (Rel). The four categories are (a] < (b] < (c) < (d] with $(279.097,323.82]<(323.82,368.364]<(368.364,412.909]<(412.909,457.454]$
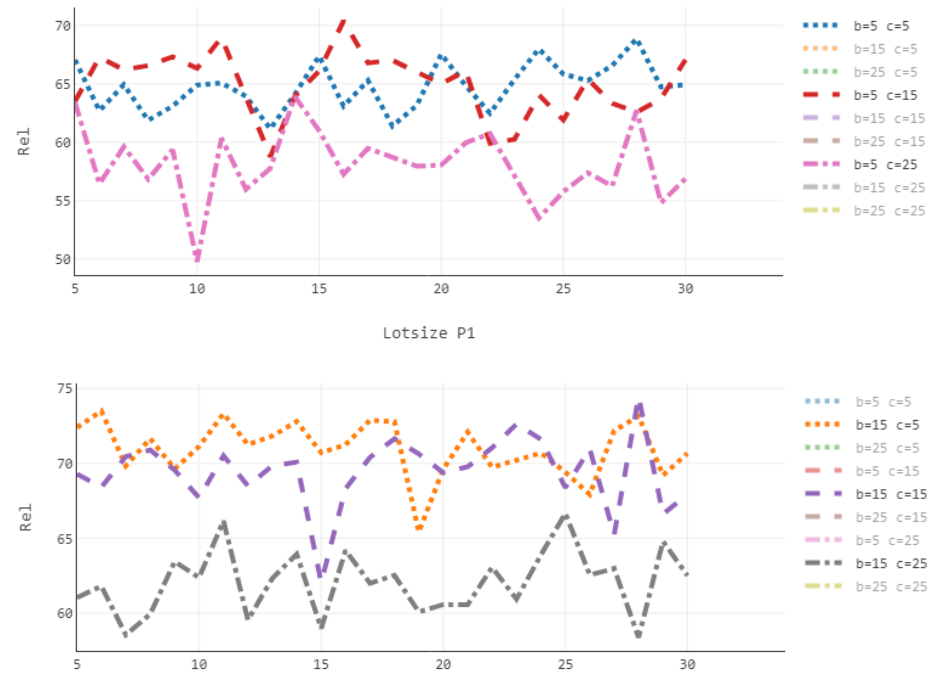

Lotsize P1

Fig. 2. Impact of varying the lot size of product 1 on the schedule reliability. $\mathrm{b}$ and $\mathrm{c}$ are representing the lot sizes of the second and third product. 
Furthermore, it can be seen in Fig. 2 that varying the lot size by one unit and keeping the rest of the parameters stable results in wavering delivery reliability. On special occasions, a bad combination of lot sizes can reduce the schedule reliability down to $50 \%$. In addition to that, the plots indicate a medium and low lot size for the third product resulting in better schedule reliability on average over varied lot size for product 1 which matches the findings for the optimized lot size.

\section{Conclusion and future research}

The mathematical model shows that optimal lot sizing does not necessarily result in high logistic KPIs considering only the cost. Additionally, the study showed that the Andler lot size leads to increased performance with higher total cost. Optimizing the lot size to the specific scenario can increase the KPIs considering only a marginal raise in total cost. Based on the assumption that the order handling strategy is a mixture between make-to-stock and make-to-order and no safety stock is available, increasing the lot size can be useful to a certain extent.

Given the fact that the model considers only a short time frame, ten periods representing one day of work, it can be expected the overall complexity will increase with longer time frames and more variants of products. The research presented in this paper provides the framework for a more detailed investigation on the effects of logistic KPIs to the lot size. Based on this, the simulation model can be adjusted by different aspects, for example job scheduling, transport and waiting processes.

\section{References}

1. Schoensleben, P.: Integral Logistics Management. 4th Ed., CRC Press, Boca Raton (2012).

2. Schuh, G.: Produktionsplanung und -steuerung: Grundlagen, Gestaltung und Konzepte (engl. title: Production planning and control)., 3rd Ed., Springer, Berlin (2006).

3. Wagner, H.M., Whitin, T.M.: Dynamic Version of the Economic Lot Size Modell. Management Science 5 (1), 89 (1958).

4. Karimi, B., Fatemi Ghomi, S.M.T., Wilson, J.M.: The capacitated lot sizing problem: a review of models and algorithms. Omega31(5), 365-378 (2003).

5. Harris, F.W.: How many Parts to make at once. Factory - the Magazine of Management 10 (2), 135-136 (1913).

6. Andler, K.: Rationalisierung der Fabrikation und optimale Losgrösse (engl. title: Economization of production and optimallot size). Oldenbourg, Munich (1929).

7. Münzberg, B.: Multikriterielle Losgrößenbildung (engl.title: Multicriterial lot sizing). Berichte aus dem IFA, PZH. Garbsen (2013).

8. Drexl, A., Haase, K.: A new type of model for multiitem capacitated dynamic lotsizing and scheduling. Manuskripte aus den Instituten für Betriebswirtschaftslehre der Universität Kiel, No. 286, Universität Kiel, Institut für Betriebswirtschaftslehre. Kiel (1992).

9. VDI-Richtlinie 4499 Blatt 1 „Digitale Fabrik - Grundlagen“. Beuth, Berlin (2008).

10. Bracht U., Geckler D., Wenzel S.: Digitale Fabrik. Springer VDI, Heidelberg (2011).

11. Stadtler, H.: How important is it to get the lot size right?. Zeitschrift für Betriebswirtschaft: ZfB 77 (4), 407 (2006). 